\title{
The effect of recalling paracetamol on hospital admissions for poisoning in Western Australia
}

\author{
Stephen R Kisely, David Lawrence and Neil J Preston
}

\begin{abstract}
SEVERAL STUDIES have investigated whether restrictions on the availability of paracetamol in Europe and Australia have affected rates of mortality, hepatotoxicity and non-fatal self-poisoning from the drug. ${ }^{1-6}$ Restrictions in Europe have included a cap on the amount of paracetamol available at a single purchase without prescription, and limiting sales to blister packs. ${ }^{4}$ In France, paracetamol may only be purchased from pharmacies and the content of each pack is legally limited to eight grams. ${ }^{2}$

In Australia, following extortion threats to two pharmaceutical companies, products containing paracetamol were recalled on two occasions in $2000 .^{6}$ We assessed the effect of the recall in Western Australia, where all admissions to hospital are recorded on a single database.
\end{abstract}

\section{METHODS}

We extracted data from the Hospital Morbidity Data System, which records all admissions to private and public hospitals throughout WA. Diagnoses were coded using ICD-9-CM ${ }^{7}$ until 30 June 1999, and then ICD-10. ${ }^{8}$ We extracted all admissions for poisoning (ICD-9-CM, 960-979; ICD-10, T36T50) from 1 January 1996 to 31 December 2001. Paracetamol overdoses were identified using the codes 965.4 (ICD-9-CM) and T39.1 (ICD-10). We also identified admissions where the principal poisoning agent was aspirin (ICD-9-CM, 965.1; ICD-10, T39.0) or ibuprofen (ICD-9-CM, 965.6; ICD-10,

\section{ABSTRACT}

Objectives: To assess the effect of two recalls of paracetamol products on rates of intentional and unintentional overdoses of paracetamol in all age groups, as well as any effect on poisoning by other agents.

Design: A before-and-after epidemiological study using data from the Western Australian Health Services Research Linked Database, which records all admissions to public and private hospitals throughout the State.

Main outcome measures: Hospital admissions in Western Australia for poisonings with all agents, including paracetamol and other over-the-counter analgesics.

Results: There were 11752 admissions for poisoning from 1996 to 2001.

Paracetamol was the primary poisoning agent in 2266 (19.3\%) admissions, aspirin in $120(1 \%)$ and ibuprofen in $277(2 \%)$. There was a significant decrease in the admission rate for paracetamol poisoning when sales were restricted in 2000 (rate ratio, 0.82; $95 \% \mathrm{Cl}, 0.68-0.99)$ compared with the same period in other years. There was no increase in poisoning with other agents at this time. However, admissions for paracetamol overdose also showed a large random variation that tended to obscure any effect.

Conclusions: Our study highlights the need to control for random as well as seasonal fluctuations in admission rates, and for restrictions on paracetamol sales to last for several months across all retail outlets. Limiting access to paracetamol may reduce paracetamol poisonings without a coincident increase in the use of other agents

MJA 2003; 178: 72-74

T39.3), as well as all other poisoning agents.

We considered intentional and unintentional overdoses in all age groups of all agents, including paracetamol and other over-the-counter analgesics, as it is difficult to distinguish between intentional and unintentional self-poisoning. ${ }^{9}$ In addition, the effect of paracetamol availability on accidental overdoses by children has only been considered in one previous study. ${ }^{6}$ We considered poisonings by all agents, as it has been suggested that restricting the

\footnotetext{
University Department of Psychiatry at Fremantle Hospital, University of Western Australia, Fremantle, WA.

Stephen R Kisely, FRANZCP, FAFPHM, Associate Professor.

Institute for Child Health Research, West Perth, WA.

David Lawrence, PhD, Postdoctoral Fellow.

Mental Health Directorate, Fremantle Hospital and Health Service, Fremantle, WA.

Neil J Preston, MSc(Psychol), Research Psychologist.

Reprints will not be available from the authors. Correspondence: Dr S R Kisely, Professor of Health Outcomes, Department of Psychiatry, Dalhousie University, Abbie J Lane Memorial Building, 5909 Veterans Memorial Lane, Suite 9211, Halifax, NS B3H 2E2, Canada. stephen.kisely@cdha.nshealth.ca
}

availability of paracetamol may lead to an increase in deliberate self-harm involving other agents. ${ }^{6}$

Paracetamol manufactured by Herron (Tennyson, QLD) was recalled from 16 March to 21 May 2000, and paracetamol made by Smith-KlineBeecham (Boronia, VIC) from 6 June to 23 August $2000 .{ }^{6}$ The recall lasted 146 days, so each person in the population contributed 146 days at risk each year. The admission rate for overdoses was calculated during this period, and for the same period of other years. Admission rates were also calculated for the remainder of each year with the WA population (1.3 million) as denominator. ${ }^{10}$

As poisonings and attempts at deliberate self-harm may be subject to seasonal fluctuations, time series analysis techniques were used to test for any significant change in the rate of hospital admissions following overdose of paracetamol during the period of sales restriction. We used the $\mathrm{X}-11$ procedure $^{11}$ to 
identify any seasonal fluctuations and adjust the series accordingly. ARIMA modelling $^{12}$ was used to test for any significant interruption to the time series during the period of restriction. All analyses were conducted using SAS software. $^{13}$

\section{RESULTS}

There were 11752 hospital admissions in WA for poisoning from 1996 to 2001. Paracetamol was the primary poisoning agent in $2266(19.3 \%)$ admissions, aspirin in $120(1 \%)$ and ibuprofen in 277 (2\%). Admission rates for overdoses of each agent are shown in Box 1 in the recall period compared with the same period in each other year. There was a statistically significant decrease in the admission rate for paracetamol poisoning when sales were restricted in 2000 (Box 1). There was no increase in poisoning with other agents at this time.

These data were further analysed using weekly time series, as the recall period did not correspond with whole months. We found a non-significant reduction of 1.1 per week (95\% CI, -2.4 to 0.1 ) in the admission rate for paracetamol poisoning, from an average of 7.3 per week $(z=-1.69 ; P=0.09)$. Paracetamol overdoses were no more or less common at any time of the year (Box 2). There were similar results when accidental poisonings and deliberate self-harm were considered separately. We found no increase in admission rates for poisoning with other agents while paracetamol was restricted (Box 3).

\section{DISCUSSION}

Although other studies have demonstrated an association between reductions in the availability of paracetamol and measures of poisoning, ${ }^{2-4}$ it is important to assess the effect on poisonings from other agents, ${ }^{5,6}$ and to assess random as well as seasonal variations in rates.

Our study had insufficient power to examine the effect on mortality rates. We were only able to measure the effect of the recall on poisonings requiring hospital admission and to establish a possible association rather than a causal relationship. Furthermore, we were unable to assess how sales of other paracetamol brands changed, and for the possibility that other factors influenced our results.

However, in contrast to a smaller study from New South Wales ( $n=143),{ }^{6}$ we found a significant fall in admissions for paracetamol overdose during the recall. This was not reflected in the same period in other years, thereby controlling for seasonal variation and reporting bias inherent in routine databases. Importantly, there was no increase in the admission rate for poisoning with other agents. However, admissions for paracetamol overdose showed a large random variation that tended to obscure any effect.

Our study suggests restrictions on paracetamol sales need to last for several months across all retail outlets for a more definite effect. Paracetamol availability was restricted in Australia for only four months, with the first recall affecting mainly supermarkets and the second pharmacies. ${ }^{6}$ Other studies that have found falls in measures of paracetamol poisoning have covered 4-36 months of restriction. $^{2-5}$ The benefits of restriction

\section{1: Rate of hospital admission following overdoses, 1996-2001}

\begin{tabular}{|c|c|c|c|c|c|c|c|}
\hline & \multicolumn{2}{|c|}{$\begin{array}{l}\text { Paracetamol available } \\
(1996-1999,2001)\end{array}$} & \multicolumn{2}{|c|}{$\begin{array}{l}\text { Paracetamol } \\
\text { restricted (2000) }\end{array}$} & \multirow[b]{2}{*}{ Rate ratio } & \multirow[b]{2}{*}{$(95 \% \mathrm{Cl})$} & \multirow[b]{2}{*}{$P$} \\
\hline & Average/year & Rate $^{*}$ & Number & Rate $^{*}$ & & & \\
\hline Aspirin & 7 & 0.96 & 7 & 0.93 & 0.97 & $(0.43-2.19)$ & 0.950 \\
\hline Paracetamol & 151 & 20.56 & 127 & 16.90 & 0.82 & $(0.68-0.99)$ & 0.041 \\
\hline Ibuprofen & 20 & 2.76 & 18 & 2.40 & 0.87 & $(0.53-1.43)$ & 0.581 \\
\hline Other agent & 971 & 132.58 & 932 & 124.02 & 0.94 & $(0.87-1.00)$ & 0.062 \\
\hline
\end{tabular}

Sale of paracetamol was restricted between 16 March 2000 and 21 May 2000 and between 6 June 2000 and 23 August 2000. The same period in each other year was used for comparison. * Rate per 100000 personyears at risk.

\section{2: Hospital admissions following overdose of paracetamol:} original and seasonally adjusted series

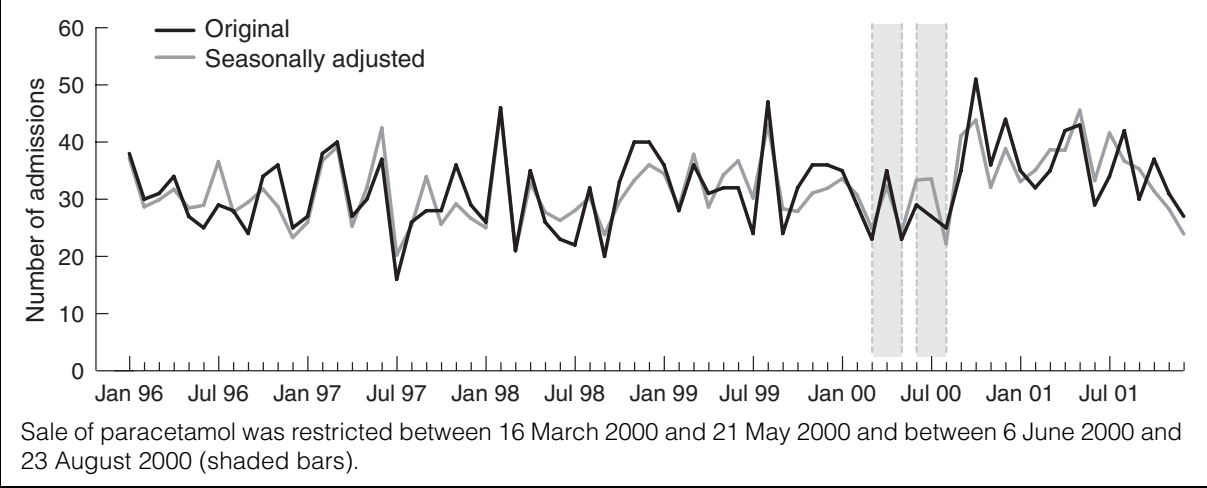

\section{3: Weekly time series of hospital admissions following overdoses, 1996-2001}

\begin{tabular}{lcccc}
$\begin{array}{l}\text { Type of } \\
\text { poisoning }\end{array}$ & $\begin{array}{c}\text { Paracetamol available } \\
(\mathbf{1 9 9 6 - 1 9 9 9 , 2 0 0 1 )} \\
\text { (average admissions/week) }\end{array}$ & $\begin{array}{c}\text { Change when paracetamol } \\
\text { restricted (2000) } \\
\text { (average change/week) }\end{array}$ & $\boldsymbol{z}$ & $\boldsymbol{P}$ \\
\hline Aspirin & 0.4 & +0.02 & +0.14 & 0.89 \\
Paracetamol & 7.3 & -1.10 & -1.69 & 0.09 \\
lbuprofen & 0.99 & -0.12 & -0.46 & 0.65 \\
Other agent & 47.8 & -2.58 & -1.24 & 0.22 \\
\hline
\end{tabular}

Sale of paracetamol was restricted between 16 March 2000 and 21 May 2000 and again between 6 June 2000 and 23 August 2000. The same period in each other year was used for comparison. 
may take several months to become apparent.

Variations in national rates of overdose may not be solely attributable to availability of paracetamol. ${ }^{9}$ Nevertheless, about half the people who overdose with paracetamol do not obtain it specifically to overdose, but use what is available. ${ }^{2}$ If packet sizes were limited, it is less likely that people would keep potentially lethal quantities at home. ${ }^{2}$ We believe that legislation to restrict availability of paracetamol should be considered given that voluntary codes of conduct have failed to reduce availability. ${ }^{14}$

\section{ACKNOWLEDGEMENTS}

The Medical Research Foundation of Fremantle Hospital and the Department of Public Health, University of Western Australia, provided funding for the study.

\section{COMPETING INTERESTS}

None identified.

\section{REFERENCES}

1. Fagan E, Wannan G. Reducing paracetamol overdoses. BMJ 1996; 313: 1417-1418.

2. Gunnell D, Hawton K, Murray V, et al. Use of paracetamol for suicide and non-fatal poisoning in the UK and France: are restrictions on availability justified? J Epidemiol Community Health 1997; 51 : 175-179.

3. Prince MI, Thomas SH, James OF, Hudson M Reduction in incidence of severe paracetamol poisoning. Lancet 2000; 355: 2047-2048.

4. Turvill JL, Burroughs AK, Moore KP. Change in occurrence of paracetamol overdose in UK after introduction of blister packs. Lancet 2000; 355 2048-2049

5. Hawton K, Townsend E, Deeks J, et al. Effects of legislation restricting pack sizes of paracetamol and salicylate on self poisoning in the United Kingdom: before and after study. BMJ 2001; 322: 1203-1207.

6. Balit C, Isbister G. Paracetamol recall: a natural experiment influencing analgesic poisoning. Med $J$ Aust 2002; 176: 162-165.
7. National Coding Centre. The official NCC Australian version of the International Classification of Diseases, 9th Revision, Clinical Modification (ICD-9 CM). Sydney: National Coding Centre, 1996.

8. World Health Organization. International Statistical Classification of Diseases and Related Health Problems (ICD-10). Geneva: WHO, 1992

9. Poulin C. Prevention of paracetamol poisoning. Lancet 2000; 355: 2009-2010.

10. Australian Bureau of Statistics. Population by age and sex, Western Australia. Perth: ABS, 1996-2001. (Catalogue no. 3235.5.)

11. US Bureau of the Census. The $X-11$ variant of the census method II seasonal adjustment program. Technical Paper No. 15, 1967 revision. Washington, DC: US Government Printing Office, 1967

12. Box GEP, Jenkins GM, Reinsel GC. Time series analysis: forecasting and control. 3rd ed. Englewood Cliffs, NJ: Prentice Hall, 1994.

13. SAS System for Windows [computer program]. Version 8. Cary, NC, SAS Institute, 1999.

14. Slaven J, Kisely S. The Esperance primary prevention of suicide project. Aust N Z J Psychiatry 2002 36: 617-621.

(Received 30 May, accepted 23 Sep 2002)

\section{book reviews}

\section{No-nonsense approach to Alzheimer's}

Alzheimer's disease. Ralph W Richter and Brigitte Z Richter. London: Mosby, 2001 (128pp, \$41.99). ISBN 0723432635.

A SMALL BOOK for a big subject best describes this concise yet comprehensive handbook on Alzheimer's disease. The authors have backgrounds in neurology, psychiatry and pharmacy, and have written a book that complements the plethora of similar short books on Alzheimer's disease that are currently available.

In a practical, no-nonsense style it covers the usual topics of diagnosis, disease stages, neuropathology, and drug treatment. It also includes information on diagnostic biomarkers for Alzheimer's disease, explanations of the various cognitive tests that may be used, and an excellent chapter on current therapies that goes far beyond the cholinesterase inhibitors. The authors have also been adventurous in looking ahead at possible new approaches to treatment.

There are a few negatives. As with any published material, some sections will be out of date very quickly and this has happened with the information on amyloid immunisation. The contact list is almost entirely North American, with a little United Kingdom information. However, the reference list is multinational, with contributions from many countries.

The book is reasonably priced at $\$ 42$. It is intended as an overview for the general practitioner, but it would also be very useful for health professionals working in the dementia field who are looking for more information, particularly in the area of current therapies.

Susan E Kurrle

Rehabilitation and Aged Care Physician Hornsby Ku-ring-gai Hospital, Hornsby, NSW

\section{Valuable resource on MS}

Multiple sclerosis. Sharon Warren and Kenneth Warren. Geneva: World Health Organization, 2001 (ix+123pp, \$59.40) ISBN $924156203 \mathrm{X}$.

THE LAST FIFTEEN YEARS have seen not only an exponential growth in published research on multiple sclerosis but also an abundance of books on the subject. Despite this abundance, this relatively small paperback fills a real void in the market.

The book reviews, summarises and provides an objective and considered opinion on epidemiological research into multiple sclerosis. It covers issues relating to diagnosis as well as research methodology, case-ascertainment methods, prevalence and incidence rates, environmental risk factors, genetic susceptibility, other risk factors and prognostic factors.

The authors are eminent Canadian multiple sclerosis researchers. They provide an overview of the subject and bring together research from around the world in order to answer some of the difficult questions that our patients often ask. They do this by discussing, in depth and detail, the methodological aspects and the results of these studies in simple language. A separate section deals with prognostic indicators and the last chapter addresses challenges for future research.

Multiple sclerosis should appeal to a wide range of readers, but especially to those starting out in the field, such as clinicians or researchers. It is scientific in its prose, but relatively easy to read for a person with multiple sclerosis who wants to know what the current state of knowledge is without spending a lot of money.

It is not a book for those readers looking for information on the scientific aspects of the genetic basis of the disease or its management. It does, however, include a very good section on the epidemiological research into genetic susceptibility.

I think the authors should be congratulated on producing a small, easy-to-read, comprehensive and objective book. It lends itself to a wide range of readers and should be updated regularly. For those of us who try but can't always manage to read all that we want to on multiple sclerosis, the book is a valuable and easily accessible reference source.

Garry D Pearce

Medical Director Multiple Sclerosis Society, NSW 